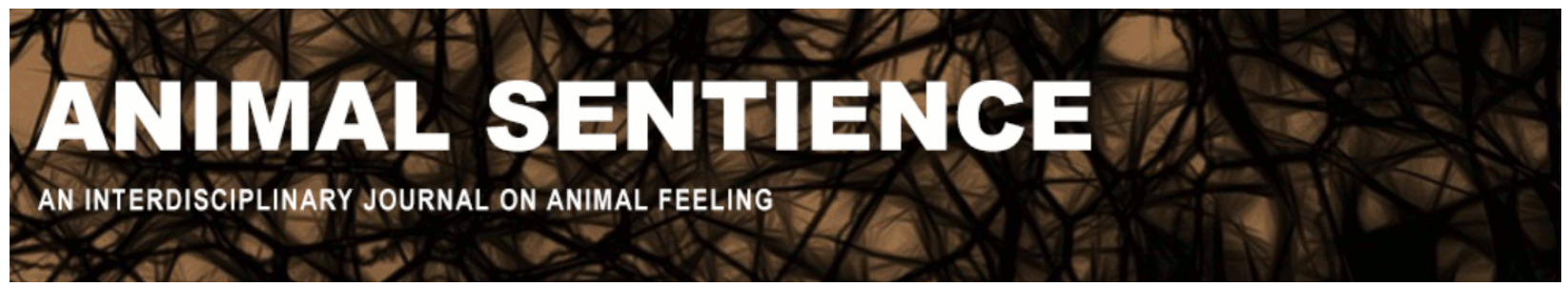

Durham, Debra (2016) The science of sentience is reshaping how we think about animals. Animal Sentience 5(7)

DOI: $10.51291 / 2377-7478.1003$

Date of submission: 2015-03-15

Date of acceptance: 2015-12-13

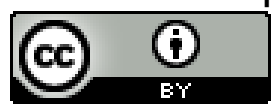

This article has appeared in the journal Animal

Sentience, a peer-reviewed journal on animal

cognition and feeling. It has been made open access,

free for all, by WellBeing International and deposited

in the WBI Studies Repository. For more information,

please contact

wbisr-info@wellbeingintl.org.

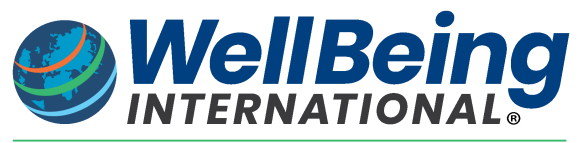

SOLUTIONS FOR PEOPLE, ANIMALS AND ENVIRONMENT 
Durham, Debra (2016) The science of sentience is reshaping how we think about animals. Animal Sentience 5(7)

DOI: $10.51291 / 2377-7478.1003$

Date of submission: 2015-03-15

Date of acceptance: 2015-12-13

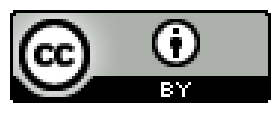

Cover Page Footnote

This commentary is available in Animal Sentience: https://www.wellbeingintlstudiesrepository.org/animsent/vol1/ 


\title{
The science of sentience is reshaping how we think about animals
}

\author{
Commentary on Broom on Animal Welfare
}

\author{
Debra Durham \\ Terra Mar Research
}

\begin{abstract}
Broom's Sentience and Animal Welfare (2014) provides its readers with an excellent overview of the evolving role of sentience in our understanding animal welfare as well as insights into why sentience matters for practice and policy.
\end{abstract}

\begin{abstract}
Debra Durham debra.durham@gmail.com is an ethologist who specializes in how animals respond to change and stress. She has studied animals both in their natural habitats and in captivity. Her research interests include psychology, resilience and behavioral plasticity. Much of her current work focuses on how applied research can be used to strengthen animal conservation and sanctuary care in practice. http://www.terramarresearch.org
\end{abstract}

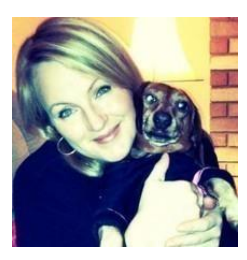

Donald Broom, Professor Emeritus of Animal Welfare at the University of Cambridge, sets the tone for this slim volume noting that one aim of the book is to challenge "widely stated human prejudices" (Broom, 2014). Chief among these is the bright line of difference between humans and other animals and the seemingly irrational distinctions often drawn between the needs and capabilities of mammals versus those in other taxonomic groups such as birds or fish. Emphasizing that "the more different from humans an animal appears to be, the less likely it is to be evaluated as sentient," he acknowledges that judgments of similarity and difference "do not always take account of biology in the way that a scientist would evaluate it." Broom's efforts to provide the historical context of welfare science and to ensure precise, scientific definitions provide a solid foundation for his thorough exploration of the components of sentience and its scientific study (Chapters 4-7). Broom then explores how consideration of sentience in welfare challenges a range of issues, such as consumer habits, environmental concerns, public policy and the academic discipline of animal welfare itself (Chapters 8-11).

As part of his larger insistence on careful, scientific definitions and precise thinking when it comes to animal welfare, Broom has provided an expanded definition of sentience that is broader than earlier iterations that includes certain abilities for awareness, feelings, memory, assessment of risks and benefits, as well as the perception and evaluation of what other individuals do. To this end, the chapters on the science of sentience address cognitive ability, feelings and emotions, awareness, consciousness, motivation, and needs in some depth. While a number of these realms have been considered in animal welfare science for decades, others have been neglected to one degree or another. The emphasis on science reflects Broom's view of the interplay between science and society in shaping welfare. The public has greater access to scientific research about animals and welfare such that "unscientific prejudice is becoming less 
important" in decisions about what standards are accepted, what laws are adopted and what products are purchased.

In the chapter on welfare assessment, Broom covers a range of approaches from the basic practical principles of measuring both positive and negative welfare to the use of animalcentered indicators that have gained traction in recent years. He also provides examples of powerful, newer approaches used for the assessment and care of individuals. Given that psychological research and assessment extend and exemplify Broom's point that scientific understanding leads us to acknowledge more similarities across species, I was somewhat surprised that he did not mention psychological assessment per se. Studies have addressed a range of psychological topics in other animals, from describing depression in dogs to measuring personality in invertebrates. By now the body of evidence is more than enough material to fill a veterinary textbook on mental health. Realizing that this book was not intended to provide exhaustive coverage, l'd suggest that instructors or students who want to consider psychology can readily address this small gap in the coverage by drawing upon the primary literature and other texts.

One challenge for any broad, interdisciplinary exploration of a complex topic like sentience or welfare is that definitions and methods differ across fields. Additionally, the understanding of sentience has expanded, shifted and been refined considerably over a relatively short period of time. These are issues that the author handles skillfully. Indeed, the interdependencies among the elements of sentience is a common thread throughout Sentience and Animal Welfare. The book refuses to shy away from complexity - a refreshing approach given the mechanistic and reductive views of welfare and sentience that have dominated for decades. What does this mean for animal welfare in practice? Broom calls upon researchers and welfare practitioners to be bold: "No concept should be avoided because there might be those who would criticize the use of complex concepts on the grounds that there must be parsimony in all description. If the subject is complex, some of the concepts must be complex."

By synthesizing concepts, providing context, and bringing the reader up-to-date on the science, this volume fills an important space in the animal welfare literature. It is important, accessible and compelling; hence, it will be useful to specialists and non-specialists alike. Whether used as a classroom text or a reference volume, Sentience and Animal Welfare will provide valuable information and perspicacious insights from Professor Broom, a seminal thought leader in animal welfare.

\section{References}

Broom, D.M. (2014) Sentience and animal welfare. Wallingford: CABI. 